\title{
Variations in structure and saccharification efficiency of biomass of different sorghum varieties subjected to aqueous ammonia and glycerol pretreatments
}

\author{
Shereena P. Joy ${ }^{\mathrm{a}}$, A. Ashok Kumar ${ }^{\mathrm{b}}$, Sunita Gorthy ${ }^{\mathrm{b}}$, Jayakumar Jaganathan ${ }^{\mathrm{b}}$, \\ Anil Kunappareddy ${ }^{\mathrm{b}}$, Anil Gaddameedi ${ }^{\mathrm{b}}$, Chandraraj Krishnan ${ }^{\mathrm{a}, *}$ \\ ${ }^{a}$ Department of Biotechnology, Indian Institute of Technology Madras, Chennai 600036, India \\ ${ }^{\mathrm{b}}$ International Crops Research Institute for the Semi-Arid Tropics, Hyderabad, Telangana, 502 324, India
}

\section{A R T I C L E I N F O}

\section{Keywords:}

Sorghum

Glycerol pretreatment

Ammonia pretreatment

Cellulose digestibility

Xylan removal

Extractives

\begin{abstract}
A B S T R A C T
Sorghum biomass is a potential feedstock for lignocellulosic bioethanol production. The selection of suitable sorghum variety is essential to obtain high ethanol yield. In this paper we screened sorghum varieties belonging to sweet sorghum, post rainy sorghum, and hybrid sorghum. These varieties were screened based on their agronomic traits, amenability to pretreatment methods, and enzymatic digestibility. The sorghum biomass was pretreated using glycerol $(60 \%)$ at $190^{\circ} \mathrm{C}$ for $60 \mathrm{~min}$ and aqueous ammonia (15\%) at $120^{\circ} \mathrm{C}$ for $60 \mathrm{~min}$. The digestibility of the pretreated biomass was determined using commercial cellulase (Cellic CTec2) at 10U/g loading, and the structural changes in the pretreated biomass were analyzed by spectroscopy and scanning electron microscopy. Sweet sorghum varieties showed significant variations in phenotypic traits such as fresh stalk yield, dry fodder yield, and juice yield. The cellulose digestibility among the sorghum varieties after the pretreatment also differed significantly. The cellulose digestibility levels of glycerol range from $64 \%$ to $89 \%$ and ammonia pretreated sorghum from $63 \%$ to $81 \%$. The total sugar yields varied from $227 \mathrm{mg} / \mathrm{g}$ to $356 \mathrm{mg} / \mathrm{g}$ and $209 \mathrm{mg} / \mathrm{g}$ to $313 \mathrm{mg} / \mathrm{g}$ for sorghum pretreated with ammonia and glycerol, respectively. Although the delignification of sorghum varieties was higher (31\%-65\%) after ammonia pretreatment than glycerol pretreatment, the cellulose digestibility was higher for the glycerol pretreated biomass. These results indicated that effect of delignification on cellulose digestibility is trivial. This study explores factors affecting pretreatment and cellulose digestibility of sorghum varieties for maximum sugar yield in the cellulosic ethanol process.
\end{abstract}

\section{Introduction}

There is an increasing demand for transportation fuel due to rapid economic development. The incessant consumption of non-renewable fossil fuels depletes the oil reserves and causes serious environmental challenges by releasing greenhouse gases. Ethanol is a promising alternative transportation fuel. It has several environmental and socioeconomic benefits. It is carbon neutral, renewable, and a value addition to crop residues. Ethanol as a fuel has a higher octane number than petrol, blends easily with gasoline, and suitable for spark ignition engines (Kang et al., 2014). Ethanol is produced from renewable sugars (first generation), lignocellulosic biomass (second generation), and algal biomass (third generation). Currently, ethanol is produced from first-generation feedstocks such as corn grains, sugarcane juice, and molasses to meet the increasing fuel-ethanol demand. Brazil and the US are the primary ethanol-producing countries, accounting for up to $80 \%$ of the world's fuel-ethanol supply (Ibeto et al., 2011). However, sugar-based sources are reliable food materials, which leads to severe conflict between food and fuel. The lignocellulosic biomass is considered as an alternative feedstock for ethanol production to avoid the competition with food supply. The lignocellulosic biomass gained much attention because of its abundant availability and low-cost. The lignocellulosic biomass has about $75 \%$ polysaccharides, comprising cellulose and hemicellulose, which are converted to ethanol (Hundt et al., 2016; Phitsuwan et al., 2013). These polysaccharides are associated with lignin to form a highly recalcitrant structure. The highly compact structure of cellulose formed by inter- and intra-hydrogen bonding with the hydroxyl groups makes it crystalline and highly resistant to

\footnotetext{
* Corresponding author.

E-mail address: kcraj@iitm.ac.in (C. Krishnan).
} 
enzymatic hydrolysis (Park et al., 2010). Hence, a pretreatment step is required to alter the lignocellulose network structure and increase cellulose accessibility to cellulases for hydrolysis. Several pretreatments using acids or alkali such as liquid hot water, ammonia fiber explosion, dilute acid treatment, and steam explosion have been employed to disintegrate the lignocellulose structure (Bhutto et al., 2017). To understand the role of cell wall components of plant biomass on cellulose and xylan's hydrolysis, there is a need to choose the appropriate pretreatment strategy, reflecting these variations. In this study, two types of pretreatment strategies - organosolv using glycerol and aqueous ammonia pretreatments were carried out on different sorghum varieties. Both ammonia and glycerol are recoverable and recyclable, making it suitable for green process. Besides, less amount of inhibitors are formed during these pretreatments. However, the acid pretreatment is corrosive and generates inhibitors detrimental to subsequent enzymatic hydrolysis and fermentation (Jönsson and Martín, 2016). Organosolv pretreatment fractionates the biomass by removing hemicellulose and lignin along with surface extractives (Mou and $\mathrm{Wu}, 2017$ ). Ammonia pretreatment causes structural changes in the biomass by breaking the lignin- carbohydrate ester bonds and partial removal of extractives (Bensah and Mensah, 2018). Unlike extractives, the ash content increases after glycerol and ammonia pretreatment (Cha et al., 2014; Qi et al., 2019).

Organosolv pretreatment fractionates biomass to separate cellulose from hemicellulose and lignin (Zhao et al., 2009), whereas ammonia pretreatment selectively removes the lignin, preserving the structural carbohydrates in biomass (Gupta and Lee, 2010). Organic solvents such as alcohols have attained interest for pretreatment due to various advantages. Low boiling point solvents like ethanol, acetone, butanol, and pentanol have been reported for pretreatment of various biomass (Teramura et al., 2016). Glycerol is an excellent low-cost solvent for biomass pretreatment. Glycerol is non-flammable, non-toxic, and a by-product of the biodiesel industry, which makes up to $10 \%$ of the production capacity (Hundt et al., 2016). Like all solvents, glycerol breaks the ether linkages of lignin carbohydrate complex and solubilizes xylan and lignin (Zhao et al., 2009). Besides, a meager amount of inhibitors form after glycerol pretreatment (Sun et al., 2015). Glycerol is a suitable solvent for the pulping process. It reduces the surface tension of biomass and helps penetrate chemicals to cleave the ether and glycosidic bonds (Demirbas, 2010; Ebrahimi et al., 2017).

Ammonia pretreatment is an extensively studied pretreatment technique for biomass since it is recoverable and relatively noncorrosive. It also serves as a nitrogen source for microbes during the subsequent fermentation process (Kim et al., 2016). There are various strategies of using ammonia as a catalyst for the breakdown of biomass, such as aqueous ammonia pretreatment, ammonia fiber explosion (AFEX), soaking in aqueous ammonia (SAA), and ammonia recycles percolation (ARP) (Mussatto, 2016). Biomass treated with ammonia undergoes delignification with alteration in the lignin structure and enhances the cellulose digestibility. Besides acting on lignin, ammonia also modifies cellulose and hemicellulose structure and increases the pore size due to swelling of biomass (Kim et al., 2016). Like glycerol pretreatment, ammonia pretreatment also does not produce inhibitors (Kumar et al., 2016).

Among various lignocellulosic feedstocks available for ethanol production, sorghum biomass is a potential source due to its higher sugar content, higher productivity (20-50 tdry/ha), low water requirement, tolerance to soil salinity and acidity (Ibeto et al., 2011). Sorghum can grow in arid, semi-arid, tropical, sub-tropical regions showing the plant's adaptability characteristics, which would help avoid the seasonal restriction of feedstocks, making it available throughout the year globally (Shoemaker and Bransby, 2010). Some of the sweet sorghum and high biomass sorghum types have a high potential for second-generation ethanol (Turhollow et al., 2010). There are many types of sorghum, and the main categories are grain sorghum, sweet sorghum, forage sorghum, and high biomass sorghum. In this study, three types, such as sweet sorghum, high biomass sorghum, and post rainy sorghum, were used as feedstock. Sweet sorghum is a climate-versatile and multipurpose crop grown primarily for its juicy stalks (nutritious livestock feed). It is also grown for food, fodder, feed, and fuel in India and many sub-Saharan Africa countries. It has wider adaptability, higher juice, brix \%, higher biomass production potential, low-water, and nutrient requirements. It is considered as one of the best alternative feedstock for bio-ethanol production and bio-energy (Nasidi et al., 2019). High biomass sorghum is also climate-versatile and multipurpose crop with wider adaptability, fast growth, high biomass production potential, resilience to drought, and benefits from non-compromise on food security as the grain is used for human consumption. It is mainly used for feedstock in second-generation biofuel production, which can improve Indian farmers' incomes in the semi-arid regions (Nagaiah et al., 2012). Post rainy sorghum is predominantly grown in the post rainy (Rabi) season, particularly in India, which requires different adaptive traits. Post rainy sorghum occupies more than $10 \%$ of the global area under sorghum, and $100 \%$ of the production goes for food and fodder use. It grows under residual soil moisture conditions and is essential for food and fodder security, especially during dry seasons in semi-arid regions of India (Reddy et al., 2004).

In this study, the effect of glycerol and ammonia pretreatment on various sorghum genotypes was analyzed to understand the factors contributing to full-sugar release in hydrolysis. Since there is no inhibitors formation in both types of pretreatment, it would negate the effect of inhibitors on enzymatic hydrolysis, thereby helping in better understanding of the role of structural components in increasing sugar yield. Mapping the sorghum traits like cellulose digestibility based on pretreatment strategy can lead to potential targets. The variation in cellulose, hemicellulose, and lignin content in sorghum varieties is correlated to hydrolysis potential (Vandenbrink et al., 2012). Corredor et al. (2009) correlated low syringyl/guiacyl (S/G) ratio and low crystallinity index to higher hydrolysis yield in forage sorghum. The guiacyl unit of lignin is responsible for lignin's inhibitory effect on the digestibility and fermentation process ( $\mathrm{Li}$ et al., 2014). Based on the pretreatment strategy, these $\mathrm{G}$ units could be modified to enhance the hydrolysis yield. However, no study has been carried out to understand the effect of pretreatment on various sorghum genotypes. Hence, analysis of factors critical for higher cellulose digestibility and overall sugar release based on pretreatment strategy was carried to screen the maximum sugar yield varieties. The present study would help identify the target sorghum variety with high potential for use as the feedstock for ethanol production.

\section{Material and methods}

\subsection{Chemicals}

Glycerol (90 \% purity) was obtained from a local vendor, aqueous ammonia $(25 \% \mathrm{v} / \mathrm{v})$ was purchased from Rankem chemical, India. Cellulase (Cellic CTec2) was obtained from Novozyme A/S, Denmark as a gift sample, HPLC grade (>99.9\%) standard sugars were purchased from Sigma Aldrich, USA. 


\subsection{Sorghum biomass}

The elite sorghum lines comprising sweet sorghum, high-biomass sorghum hybrids, and post-rainy sorghum hybrids (IS 18542, ICSV 25333, ICSA 387 x IS 17307, ICSSH 28, ICSV 93046, REHT 1005 REHT 1016 REHT 1022, and REHT 1023), were obtained from ICRISATPatancheru, India (located at an altitude of $545 \mathrm{~m}$ above mean seas level, the latitude of $17.53 \mathrm{oN}$ and longitude of $17.28^{\circ} \mathrm{E}$ in alpha lattice). The sorghum varieties were grown in two different RCBD trials (one each for sweet sorghum \& biomass sorghum and the other for post rainy sorghum) with two replications during the 2016 rainy and post rainy seasons. The plot size was two rows of $4 \mathrm{~m}$ length spaced at $75 \mathrm{~cm}$ apart with a plant-to-plant spacing of $15 \mathrm{~cm}$ within the rows in both the seasons. All the recommended agronomic practices were followed for maintaining a good crop stand. The traits (Days to $50 \%$ flowering (DFL), stem girth at ${ }^{\text {third }}$ internode (SG3), stem girth at 10th internode (SG10), number of internodes (NI), fresh stalk yield (FSY), dry stalk yield (DSY), juice yield (JY), sugar yield (SUY) plant height, brix\%, and grain yield) were recorded using standard procedures. The dry biomass from these genotypes was sent to IIT-Madras for further processing.

\subsection{Feedstock preprocessing}

The sorghum stalks were used without washing. The stalks were desized mechanically before the subsequent thermochemical pretreatment. The size of the biomass samples received was about $1-1.5 \mathrm{~cm}$. The size of the biomass was further reduced by grinding in a lab blender. The ground biomass was sieved manually through screens corresponding to $0.3-1.0 \mathrm{~mm}$. The pre-processed biomass samples were stored in airtight zip-lock bags at room temperature for further pretreatment.

\subsection{Glycerol pretreatment}

The glycerol pretreatment was carried out based on the preliminary trial (supplementary data Fig. 1) and literature (Martin et al., 2011). A $30 \mathrm{~g}$ of preprocessed sorghum stalks were taken and mixed with glycerol ( $60 \% \mathrm{w} / \mathrm{w}$ of slurry) in a $500 \mathrm{ml}$ stainless steel reactor (Amar Equipments, Mumbai). The biomass loading was $10 \% \mathrm{w} / \mathrm{w}$ on a dry weight basis. The mixture was heated at $190{ }^{\circ} \mathrm{C}$ for $60 \mathrm{~min}$ (Martin et al., 2011). The reactor was cooled down, and the slurry was filtered using a nylon filter to separate solids from spent liquor. The filtered pretreated solids were washed with an equal amount of aqueous glycerol (water to glycerol ratio of 1:1) to wash off the solubilized lignin from the solids (Guragain et al., 2011). The solids were then washed with water until the $\mathrm{pH}$ of the solids was neutral. The washed solids were air-dried and

\subsection{Ammonia pretreatment}

The conditions of aqueous ammonia pretreatment were chosen based on the previous study from our laboratory (Swain and Krishnan, 2015) and reported conditions for sorghum biomass (Vandenbrink et al., 2012). A $30 \mathrm{~g}$ of preprocessed sorghum stalks were mixed with an aqueous ammonia solution ( $15 \% \mathrm{v} / \mathrm{v})$ at $10 \% \mathrm{w} / \mathrm{w}$ solids loading in a $500 \mathrm{~mL}$ stainless steel reactor (Amar Equipments, Mumbai). The biomass mixture was heated at $120^{\circ} \mathrm{C}$ for $60 \mathrm{~min}$. After cooling the reactor, the slurry was filtered using a nylon cloth filter (purchased from a local vendor) to separate the solids from spent liquor. The pretreated solids were then washed with water until the $\mathrm{pH}$ of the solids was neutral. The washed solids were air-dried and stored in zip lock bags at room temperature for further analysis.

\subsection{Compositional analysis of biomass}

The composition of raw and pretreated biomass was determined according to the Laboratory Analytical Protocol (LAP) of the National Renewables Laboratory (Sluiter et al., 2008). The raw biomass was first extracted with water and ethanol in a Soxhlet apparatus. The biomass was dried to $<10 \%$ moisture content. A $0.3 \mathrm{~g}$ of the biomass was taken in a pressure tube and mixed with $3 \mathrm{ml}$ of $72 \% \mathrm{w} / \mathrm{w}$ sulphuric acid. The mixture was incubated at $30 \mathrm{oC}$ for one $\mathrm{h}$ in a water bath and diluted with $84 \mathrm{ml}$ of MilliQ water to a final acid concentration of $4 \%$. The diluted samples were autoclaved for $1 \mathrm{~h}$ at $121 \mathrm{oC}$. The samples were then filtered using vacuum filtration, and the amount of simple sugars in the filtrate was determined using HPLC. The acid-soluble lignin in the supernatant was determined by measuring absorbance at $240 \mathrm{~nm}$ using a UV spectrophotometer. The solid fraction was analyzed for the concentration of acid insoluble lignin and ash.

\subsection{Enzymatic hydrolysis}

The enzymatic hydrolysis of glycerol and ammonia pretreated solids were carried out in $15 \mathrm{ml}$ glass vials covered with screw caps. The pretreated dry solids $(0.2 \mathrm{~g}$ dry wt) were suspended in $10 \mathrm{ml}$ of $0.05 \mathrm{M}$ sodium citrate buffer (pH4.8) and supplemented with Cellic CTec2 cellulase (10 U/g solids). The antibiotics cyclohexamide $(1 \mathrm{mg} / \mathrm{ml})$ and chloramphenicol $(1 \mathrm{mg} / \mathrm{ml})$ were also added to the reaction mixture to avoid microbial contamination during hydrolysis. The saccharification was carried out in a shaker incubator at $50^{\circ} \mathrm{C}, 150 \mathrm{rpm}$ for $72 \mathrm{~h}$. After the hydrolysis reaction, the concentration of glucose and xylose in the hydrolysate was determined by HPLC. The efficiencies of hydrolysis of cellulose and xylan were calculated using the following equations:

Cellulose hydrolysis efficiency $(\%)=\frac{\text { Amount of glucose in the hydrolysate }(\mathrm{mg}) \times 100}{\text { Cellluloase content in pretreated solid }(\mathrm{mg}) \times 1.11}$

stored in zip lock bags at room temperature for further analysis.

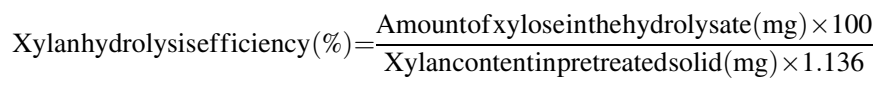




\section{Component (Glucan, Xylan, Lignin) recovery:}

2.9. Thermogravimetric (TG) analysis

Cellulose recovery $(\%)=\frac{\text { Cellulose content in pretreated biomass }\left(\frac{\mathrm{mg}}{\mathrm{g}}\right) \times \text { dry wt of pretreated biomass }(\mathrm{g}) \times 100}{\text { Cellulose content in raw biomass }\left(\frac{\mathrm{mg}}{\mathrm{g}}\right) \times \text { dry wt of raw biomass }(\mathrm{g})}$

Xylan recovery $(\%)=\frac{\left.\text { Xylan content in pretreated biomass }\left(\frac{\mathrm{mg}}{\mathrm{g}}\right)\right) \times \text { dry wt of pretreated biomass }(\mathrm{g}) \times 100}{\left.\text { Xylan content in raw biomass }\left(\frac{\mathrm{mg}}{\mathrm{g}}\right)\right) \times \text { dry wt of raw biomass }(\mathrm{g})}$

Lignin recovery $(\%)=\frac{\text { Lignin content in pretreated biomass }\left(\frac{\mathrm{mg}}{\mathrm{g}}\right) \times \text { dry wt of pretreated biomass }(\mathrm{g}) \times 100}{\text { Lignin content in raw biomass }\left(\frac{\mathrm{mg}}{\mathrm{g}}\right) \times \text { dry wt of pretreated biomass }(\mathrm{g})}$

Delignification $(\%)=100-$ Lignin recovery

\section{8. $X$ - ray diffraction $(X R D)$ analysis of biomass}

X-Ray diffraction analysis (XRD) was carried out using a D8 ADVANCE diffractometer equipped with a sealed tube of CuK $\alpha$ source. The samples were cast on microscopic slides before observation. Scans were collected from $2 \theta=10^{\circ}$ to $40^{\circ}$ in steps of $0.04^{\circ}$ at a time interval of $0.2 \mathrm{~s}$. The recitation $(\mathrm{CuK} \alpha)$ level used was $1.5406 \mathrm{~A}^{\circ}$. The crystallinity index (CrI) was determined according to (Segal et al., 1959) as given below

$\operatorname{CrI}(\%)=\left(I_{002}-I_{\mathrm{am}}\right) * 100 / I_{002}$

where $I_{002}$ is the intensity of the diffraction from the 002 plane at $2 \theta=22.4^{\circ}$ and $I_{\mathrm{am}}$ is the intensity of the amorphous region at $2 \theta=18.4^{\circ}$.
Thermogravimetric (TG) analysis of untreated and pretreated biomass was done using SDT Q600 V20.9 Build 20 (T.A Instruments, USA). A $3-5 \mathrm{mg}$ of the biomass sample was taken in an alumina pan and heated from $25^{\circ} \mathrm{C}$ to $600^{\circ} \mathrm{C}$ at a heating rate of $10^{\circ} \mathrm{C} /$ min under a nitrogen atmosphere with a gas flow rate $100 \mathrm{ml} / \mathrm{min}$ to prevent the oxidation of the sample. The weight loss was monitored and recorded.

\subsection{Scanning electron microscopy (SEM)}

The morphology of biomass was studied using a scanning electron microscope using FEI-Quanta $400 \mathrm{~F}$ (Thermo Fischer Scientific, US). The sample was placed on a carbon conductive tape stuck on pin mount specimen holder. The sample particles were pressed, and the air was blown to remove all the loosely bound particles. The samples were gold sputtered under vacuum for $120 \mathrm{~s}$ and kept in a desiccator before imaging.

\subsection{Fourier transform infra-red (FTIR) analysis}

The changes in the structure of cellulose, hemicellulose, and lignin of

Table 1

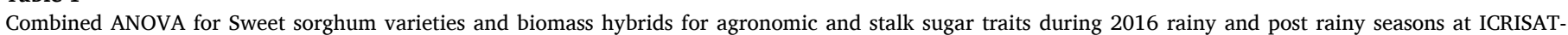
Patancheru.

\begin{tabular}{|c|c|c|c|c|c|c|c|c|c|c|c|c|}
\hline Nor & $\begin{array}{l}\text { Days to } 50 \\
\% \\
\text { Flowering }\end{array}$ & $\begin{array}{l}\text { Plant } \\
\text { height } \\
(\mathrm{m})\end{array}$ & $\begin{array}{l}\text { Stem girth@ } \\
\text { 3rd } \\
\text { internode } \\
(\mathrm{mm})\end{array}$ & $\begin{array}{l}\text { Stem girth } \\
\text { @ 10th } \\
\text { internode } \\
(\mathrm{mm})\end{array}$ & $\begin{array}{l}\text { No. of } \\
\text { Internodes }\end{array}$ & $\begin{array}{l}\text { Fresh stalk } \\
\text { yield (t } \\
\left.\text { ha }^{-1}\right)\end{array}$ & $\begin{array}{l}\text { Stover } \\
\text { yield (t } \\
\left.\mathrm{ha}^{-1}\right)\end{array}$ & $\begin{array}{l}\text { Juice yield } \\
\left(\mathrm{t} \mathrm{ha}^{-1}\right)\end{array}$ & $\begin{array}{l}\text { Brix } \\
(\%)\end{array}$ & $\begin{array}{l}\text { Sugar } \\
\text { yield (t } \\
\left.\text { ha }^{-1}\right)\end{array}$ & $\begin{array}{l}\text { Bagasse } \\
\text { yield (t } \\
\left.\mathrm{ha}^{-1}\right)\end{array}$ & $\begin{array}{l}\text { Grain } \\
\text { yield }(\mathrm{t} \\
\left.\mathrm{ha}^{-1}\right)\end{array}$ \\
\hline Replication & 18.00 & 1.62 & 0.61 & 2.21 & 0.25 & 2.53 & 3.13 & 3.78 & 8.00 & 0.28 & 28.13 & 0.25 \\
\hline Genotype & $464^{* *}$ & 1.15 & $9.93^{* *}$ & $9.16^{* *}$ & $4.893^{* *}$ & $636.98^{* * *}$ & $123.583^{* *}$ & $111.261^{* *}$ & 4.17 & $0.96^{*}$ & $240.1^{* * *}$ & 0.27 \\
\hline $\begin{array}{c}\text { Residual } \\
\text { Error }\end{array}$ & 6.00 & 0.62 & 0.26 & 0.23 & 0.69 & 2.87 & 6.04 & 3.62 & 5.67 & 0.05 & 0.46 & 0.28 \\
\hline Mean & 78.00 & 4.25 & 19.50 & 15.00 & 15.20 & 70.20 & 27.20 & 28.70 & 15.8 & 3.40 & 41.40 & 2.20 \\
\hline $\mathrm{SE}+$ & 1.73 & 0.79 & 0.36 & 0.34 & 0.59 & 1.20 & 1.74 & 1.34 & 1.68 & 0.17 & 0.48 & 0.38 \\
\hline CV (\%) & 3.10 & 18.50 & 2.60 & 3.20 & 5.40 & 2.40 & 9.00 & 6.60 & 15.1 & 6.90 & 1.60 & 23.90 \\
\hline $\mathrm{CD}(5 \%)$ & 7.80 & 2.51 & 1.62 & 1.53 & 2.63 & 5.39 & 7.82 & 6.05 & 7.58 & 0.74 & 2.15 & 1.69 \\
\hline
\end{tabular}

* Significant at $\mathrm{p} \leq 0.05, * *$ Significant at $\mathrm{p} \leq 0.01$. 
Table 2

Combined ANOVA table for biomass related traits in the post rainy season based hybrids during 2016 rainy and post rainy seasons at ICRISAT-Patancheru.

\begin{tabular}{|c|c|c|c|c|c|c|c|c|c|}
\hline $\begin{array}{l}\text { Source of } \\
\text { variation }\end{array}$ & $\begin{array}{l}\text { Days to } 50 \% \\
\text { flowering }\end{array}$ & $\begin{array}{l}\text { Plant } \\
\text { height (m) }\end{array}$ & $\begin{array}{l}\text { Plant aspect } \\
\text { score }(1-5)\end{array}$ & $\begin{array}{l}\text { Stay green } \\
\text { score }(1-5)\end{array}$ & $\begin{array}{l}\text { Lodging score } \\
(1-5)\end{array}$ & $\begin{array}{l}\text { Restoration } \\
(\%)\end{array}$ & $\begin{array}{l}100 \text { seed } \\
\text { weight }(\mathrm{g})\end{array}$ & $\begin{array}{l}\text { Grain yield ( } \mathrm{t} \\
\mathrm{ha}^{-1} \text { ) }\end{array}$ & $\begin{array}{l}\text { Stover yield ( } \mathrm{t} \\
\mathrm{ha}^{-1} \text { ) }\end{array}$ \\
\hline Replication & 6.12 & 0.00 & 0.00 & 0.28 & 0.00 & 55.12 & 0.21 & 0.01 & 0.02 \\
\hline Genotype & 2.46 & 0.02 & 0.67 & 0.70 & 0.67 & $236.79^{*}$ & 0.13 & 3.96 & 19.93 \\
\hline Residual Error & 33.46 & 0.01 & 0.00 & 0.11 & 0.00 & 26.79 & 0.06 & 0.82 & 2.97 \\
\hline Mean & 67.40 & 3.00 & 1.50 & 1.00 & 2.00 & 91.00 & 4.00 & 4.70 & 8.68 \\
\hline SE+ & 4.09 & 0.10 & 0.00 & 0.20 & 0.00 & 3.70 & 0.20 & 0.64 & 1.22 \\
\hline CV (\%) & 8.60 & 3.90 & 0.00 & 23.50 & 0.00 & 5.70 & 6.10 & 19.50 & 19.90 \\
\hline CD (5 \%) & 18.41 & 0.30 & $*$ & 1.10 & $*$ & 16.50 & 0.80 & 2.88 & 5.49 \\
\hline
\end{tabular}

* Significant at $\mathrm{p} \leq 0.05, * *$ Significant at $\mathrm{p} \leq 0.01$.

Table 3

Cell wall composition of untreated, glycerol pretreated and ammonia pretreated sorghum varieties.

\begin{tabular}{|c|c|c|c|c|c|c|c|c|c|}
\hline \multirow{2}{*}{ Sorghum variety } & \multicolumn{3}{|l|}{ Untreated } & \multicolumn{3}{|c|}{ Glycerol Pretreated } & \multicolumn{3}{|c|}{ Ammonia Pretreated } \\
\hline & Cellulose \% & Xylan \% & Lignin \% & Cellulose \% & Xylan\% & Lignin $\%$ & Cellulose \% & Xylan \% & Lignin \% \\
\hline IS 18542 & $20 \pm 1.45$ & $13 \pm 0.68$ & $20 \pm 0.36$ & $48 \pm 5.7$ & $12 \pm 1.4$ & $19 \pm 2.8$ & $49 \pm 0.71$ & $30 \pm 2.83$ & $16 \pm 0.96$ \\
\hline ICSV 25333 & $31 \pm 0.65$ & $20 \pm 0.49$ & $23 \pm 0.66$ & $39 \pm 0.7$ & $17 \pm 0.7$ & $22 \pm 3.6$ & $47 \pm 1.65$ & $28 \pm 2.12$ & $16 \pm 2.3$ \\
\hline ICSA387xIS 7307 & $28 \pm 1.23$ & $19 \pm 2.25$ & $22 \pm 0.79$ & $40 \pm 0.7$ & $12 \pm 1.4$ & $21 \pm 4.4$ & $46 \pm 0.91$ & $29 \pm 3.54$ & $18 \pm 1.74$ \\
\hline ICSSH 28 & $28 \pm 1$ & $20 \pm 0.26$ & $21 \pm 1.36$ & $46 \pm 4.2$ & $16 \pm 3.5$ & $24 \pm 0.2$ & $49 \pm 1.4$ & $29 \pm 0.71$ & $18 \pm 3.78$ \\
\hline ICSV 93046 & $28 \pm 0.65$ & $20 \pm 0.84$ & $21 \pm 1.89$ & $36 \pm 3.5$ & $19 \pm 3.5$ & $21 \pm 4.5$ & $48 \pm 3.54$ & $29 \pm 071$ & $21 \pm 2.38$ \\
\hline REHT 1005 & $21 \pm 2.36$ & $16 \pm 1.94$ & $19 \pm 0.16$ & $47 \pm 2.1$ & $14 \pm 0.7$ & $22 \pm 1$ & $46 \pm 2.83$ & $26 \pm 0.71$ & $17 \pm 4.43$ \\
\hline REHT 1016 & $26 \pm 0.86$ & $18 \pm 0.23$ & $19 \pm 0.94$ & $37 \pm 4.2$ & $15 \pm 0.7$ & $22 \pm 2.1$ & $53 \pm 2.5$ & $28 \pm 15$ & $13 \pm 0.23$ \\
\hline REHT 1022 & $19 \pm 1.34$ & $13 \pm 0.94$ & $13 \pm 0.24$ & $43 \pm 4.2$ & $10 \pm 0.7$ & $24 \pm 2.8$ & $51 \pm 2.4$ & $28 \pm 2.5$ & $18 \pm 0.34$ \\
\hline REHT 1023 & $24 \pm 0.57$ & $17 \pm 1.03$ & $19 \pm 0.75$ & $31 \pm 1.4$ & $11 \pm 0.7$ & $18 \pm 0.1$ & $48 \pm 0.64$ & $30 \pm 1.8$ & $19 \pm 2.15$ \\
\hline
\end{tabular}

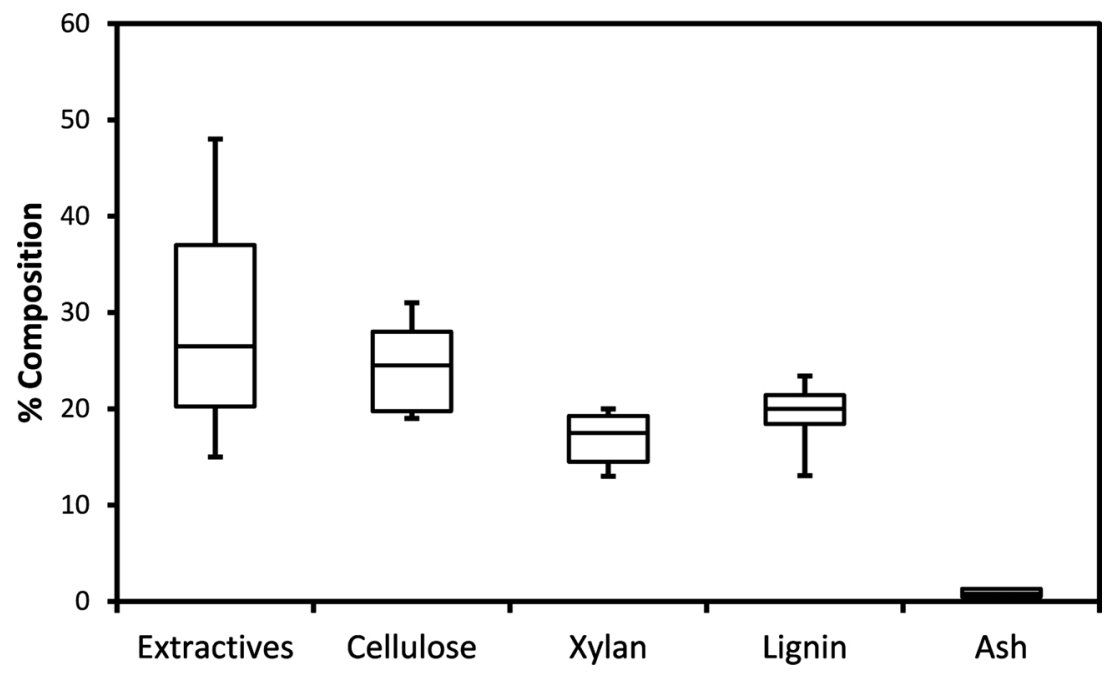

Fig. 1. Box plot showing the variation in the compositions of sorghum varieties.

untreated and pretreated samples were analyzed by FTIR using ATRFTIR Cary 630 (Agilent Technologies, US). Samples were placed on the diamond Attenuated Total Reflectance (ATR) top plate and scanned to obtain a spectrum from 4000 to $400 \mathrm{~cm}^{-1}$ range with $4 \mathrm{~cm}^{-1}$ resolution.

\subsection{HPLC quantification of sugar}

The sugars in the hydrolysate were analyzed and quantified using an HPLC system (Shimadzu Corporation, Japan) equipped with a RI detector and Aminex HPX- 87H column. A $5 \mathrm{mM} \mathrm{H}_{2} \mathrm{SO}_{4}$ was used as the mobile phase at $0.6 \mathrm{ml} / \mathrm{min}$ flow rate to elute the sugars. The column was operated at $60^{\circ} \mathrm{C}$. HPLC grade sugars were used as a standard to identify and quantify sugars in the hydrolysate.

\subsection{Statistical analysis}

Analysis of variance (ANOVA) was carried out for individual environment using General model (Steel and Torrie, 1980) and PROC GLM (Generalized Linear Model) procedure in GenStat $19^{\text {th }}$ Version to test the significant differences among genotypes. For analysis of pretreatment data, ANOVA was performed using Microsoft excel. All the experiments were performed in triplicates, and the average values with standard deviation are presented.

\section{Results and discussion}

\subsection{Performance of sorghum genotypes for agronomic traits}

Large significant variations were observed among the genotypes for the agronomic traits studied, except for plant height, brix $\%$ and grain yield (Table 1). The genotypic differences were highly significant for 


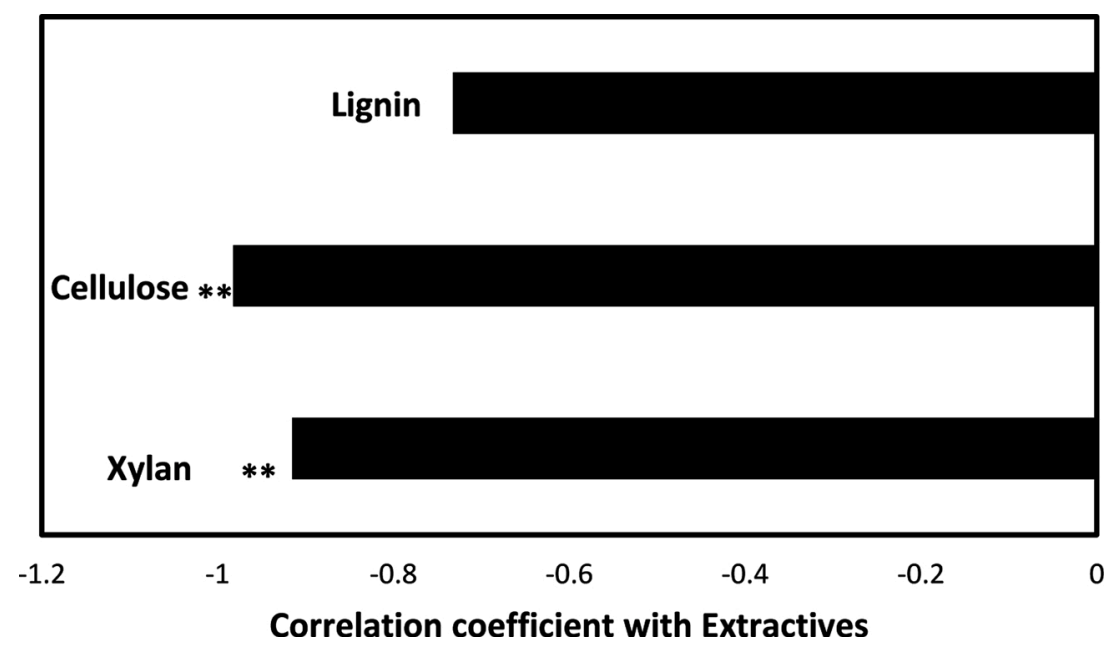

Fig. 2. Correlation of extractives with the cell wall components of sorghum varieties.

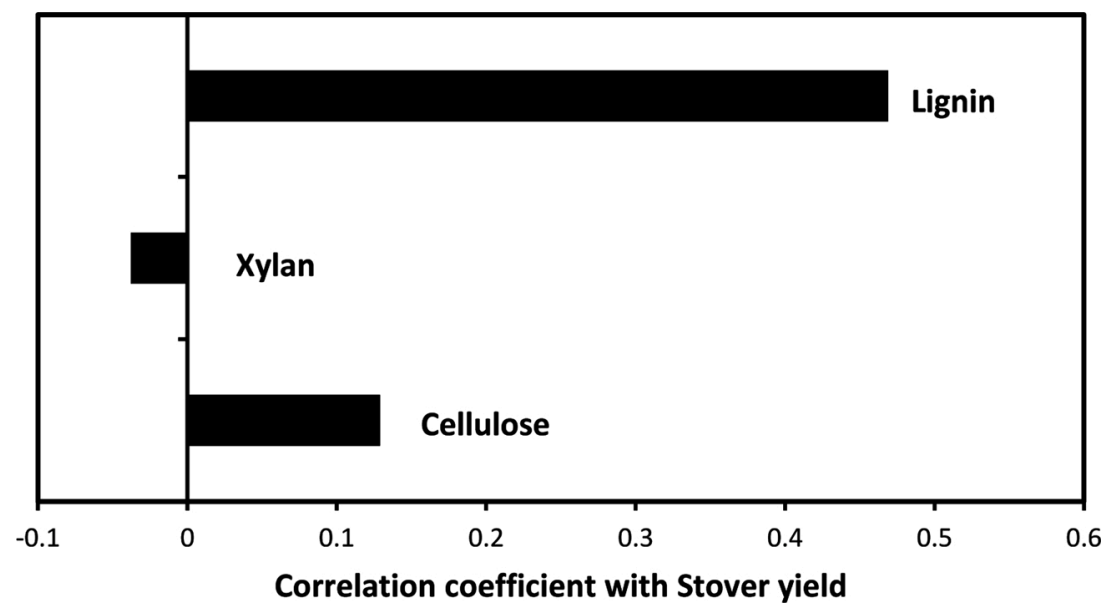

Fig. 3. Correlation of strover yield with the cell wall components of sorghum varieties.

Table 4

Cell wall component recovery after glycerol and ammonia pretreatment of sorghum varieties.

\begin{tabular}{|c|c|c|c|c|c|c|}
\hline \multirow{2}{*}{ Sorghum variety } & \multicolumn{3}{|l|}{ Glycerol Pretreated } & \multicolumn{3}{|l|}{ Ammonia Pretreated } \\
\hline & Cellulose recovery \% & Xylan recovery \% & Delignification \% & Cellulose recovery \% & Xylan recovery \% & Delignification \% \\
\hline IS 18542 & 100 & 43 & 57 & 100 & 100 & 60 \\
\hline ICSV 25333 & 100 & 70 & 21 & 96 & 88 & 56 \\
\hline ICSA387xIS 7307 & 100 & 45 & 35 & 100 & 87 & 49 \\
\hline ICSSH 28 & 100 & 56 & 28 & 100 & 99 & 49 \\
\hline ICSV 93046 & 98 & 71 & 23 & 100 & 100 & 43 \\
\hline REHT 1005 & 100 & 43 & 43 & 100 & 83 & 47 \\
\hline REHT 1016 & 95 & 54 & 26 & 100 & 81 & 65 \\
\hline REHT 1022 & 96 & 33 & 22 & 100 & 100 & 31 \\
\hline REHT 1023 & 90 & 45 & 35 & 100 & 94 & 49 \\
\hline
\end{tabular}

fresh stalk yield, stover yield, juice yield, and sugar yield. Among the biomass hybrids studied, barring for restoration $\%$, the differences among genotypes were not significant (Table 2).

The mean performance of different sweet sorghum varieties, biomass hybrids, and post rainy sorghum hybrids for different agronomic traits showed large variability (Table 1 ). The analysis of variance (ANOVA) revealed that the mean sum of squares among the four sweet sorghum genotypes IS 18542, ICSV 25333, RVICSH 28 / ICSSH 28, and ICSV 93046 were significantly $(\mathrm{p}<0.05)$ different for traits, days to $50 \%$ flowering (DFL), stem girth at 3rd internode (SG3), stem girth at 10th internode (SG10), number of internodes (NI), fresh stalk yield (FSY), dry stalk yield (DSY), juice yield (JY) and sugar yield (SUY) (Table 1). The genotypes also exhibited highly significant $(\mathrm{p}<0.01)$ differences for all the traits except for plant height, grain yield, and brix\%. The bagasse yield for IS18542 was higher compared to all other genotypes. There was no significant difference in plant height. All the genotypes exhibited a very high uniformity level, as indicated by a low CV\% except for the grain yield. The grain yields for IS 18542, ICSV 25333, and ICSV 93046 were higher than RVICSH 28 / ICSSH 28. The fresh stalk yield was highest for IS18542 with a yield of $96.5 \mathrm{tha}^{-1}$. These data suggest a high degree of variability among the genotypes for the agronomic traits, which offer an excellent opportunity to harness high sugar yield with 


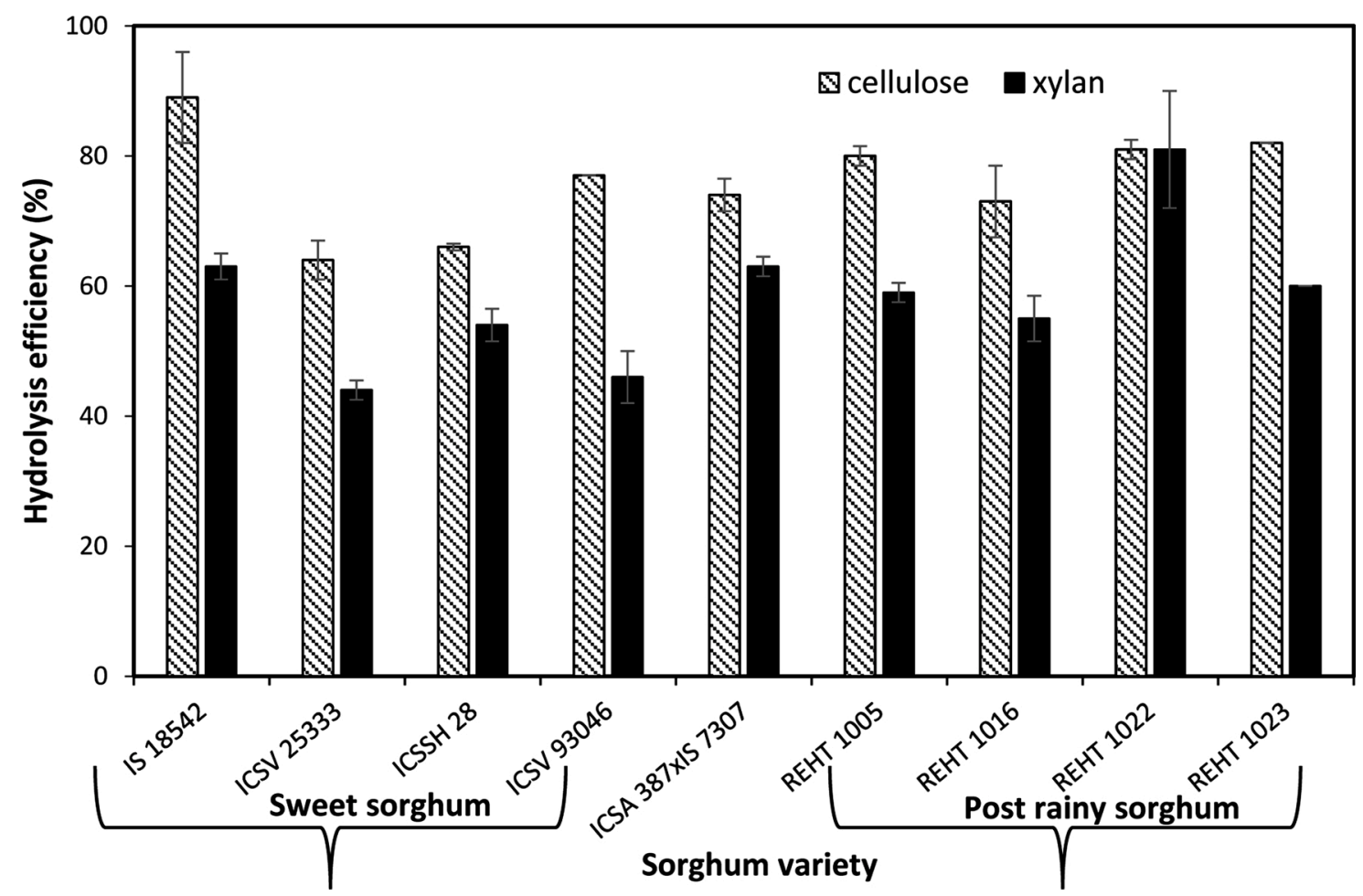

Fig. 4. Comparison of cellulose and xylan hydrolysis efficiency of among glycerol pretreated sorghum varieties.

their genetic superiority. In the case of post rainy sorghum hybrids, there was no significant difference among the genotypes REHT 1005, REHT 1016, REHT 1022, and REHT 1023 for agronomic traits studies except for restoration percentage (Table 2). REHT 1023 hybrid has performed better than the other three post rainy season hybrids with $11.75 \mathrm{t} \mathrm{ha}^{-1}$ stover yield and $5.85 \mathrm{t} \mathrm{ha}^{-1}$ grain yield.

\subsection{Compositional diversity in sorghum varieties}

The study of nine different sorghum genotypes showed variation in the cellulosic polysaccharide composition of stalks (Table 3). As shown in Fig. 1, the variation was less for lignin and ash content but higher for extractives, including the soluble sugars. There was no significant

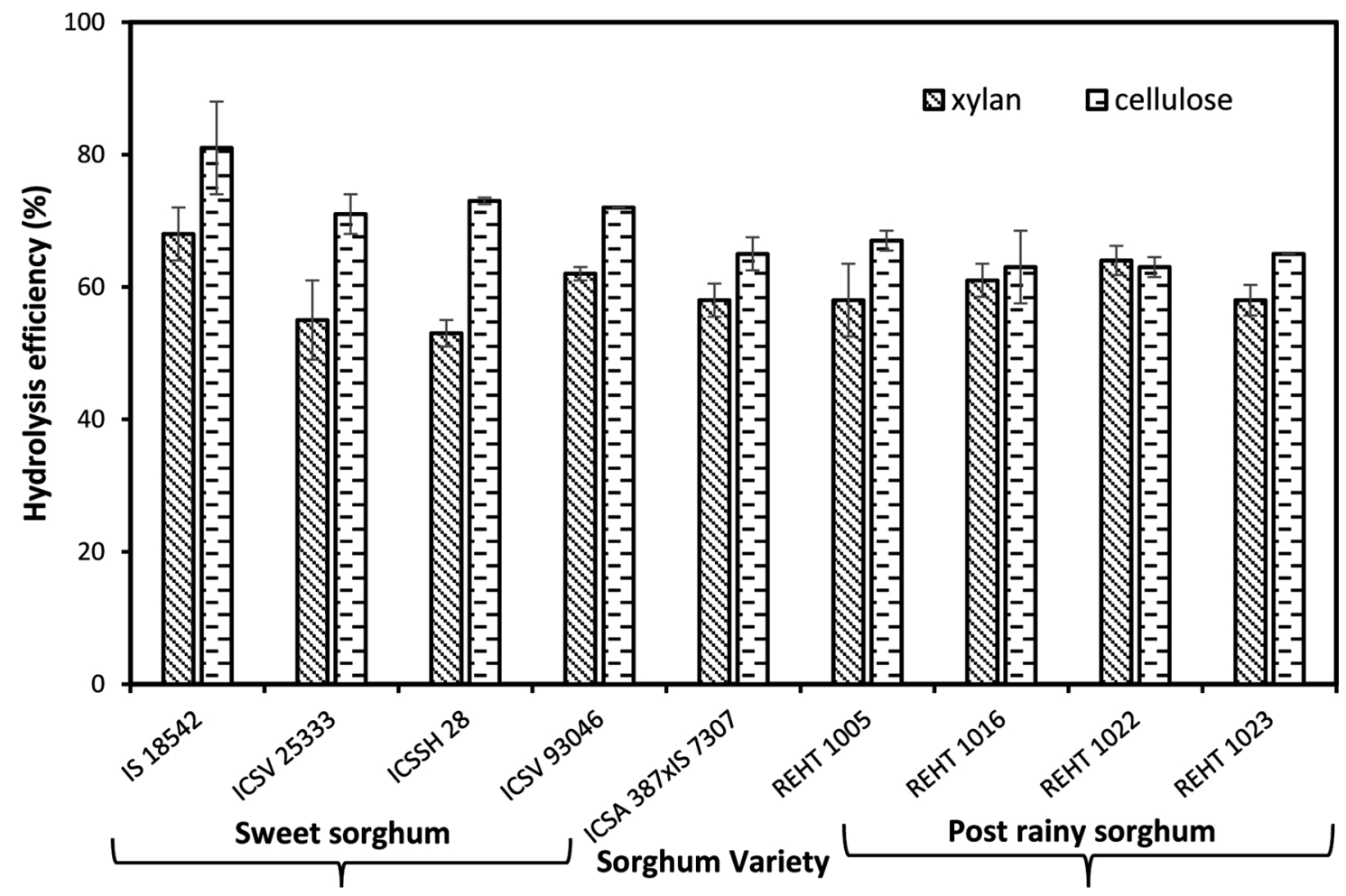

Fig. 5. Comparison of cellulose and xylan hydrolysis efficiency of among ammonia pretreated sorghum varieties. 
variation in cellulose, xylan, and lignin contents between sweet sorghum varieties and post rainy varieties of sorghum. The hybrid sorghum variety also showed similar cell wall composition. The cellulose and xylan contents in all sorghum varieties varied from $20 \%$ to $31 \%$ and $13 \%-$ $20 \%$, respectively. The lignin content did not show significant variation and was mainly in the range of $19 \%-23 \%$ except for the REHT 1022sorghum variety, which had only $13 \%$ lignin. The ash content in all the varieties was low and ranged from 0.3 to $1.6 \%$. It was observed that the sorghum varieties with high extractives had low concentrations of cellulose and xylan (Fig. 2). Hence, sorghum with lower extractives is suitable for obtaining high sugar yield during hydrolysis. While there was no significant correlation between the stover yield and the cell wall composition, lignin content showed a better positive correlation (Fig. 3). This result indicates that lignin plays a significant role in biomass production (Li et al., 2014). Thus, the study on the compositional variations in different sorghum genotypes emphasized the role of extractives and lignin on biomass composition and production.

\subsection{Effect of glycerol pretreatment on sorghum genotypes}

The sorghum biomass undergoes drastic changes in its cell wall structure and composition after pretreatment, which improves the accessibility of cellulose to the hydrolytic enzymes. Glycerol pretreatment partially solubilizes both hemicellulose and lignin (Table 4). Unlike the ammonia pretreatment, which acts specifically on lignin, the glycerol pretreatment fractionates the biomass into different components (Mussatto, 2016; Sun and Chen, 2008). Similar to the phenotypic traits, the post rainy varieties showed little variation in the cellulose digestibility after the glycerol pretreatment. In contrast, the variation in cellulose digestibility was significant for sweet sorghum varieties. The genotype IS18542 showed maximum cellulose digestibility of $89 \%$ (Fig. 4). Similar to cellulose hydrolysis, xylan hydrolysis also showed a similar profile, wherein the sweet sorghum varieties showed significant variations. However, the post rainy varieties showed similar yield except for REHT1022, which showed higher xylan hydrolysis efficiency of 81
$\%$. There was also no significant difference in the cellulose digestibility between sweet sorghum and post rainy varieties. The cellulose saccharification differences are due to the significant variation ( $p<0.05$ ) in xylan removal among sweet sorghum varieties, as shown in Supplementary data Table 1 . All the glycerol pretreated sweet sorghum varieties showed xylan and lignin removal, ranging from $29 \%$ to $57 \%$ and $21 \%-57 \%$, respectively. The correlation results also showed that both lignin removal and xylan recovery, along with cell wall components, played a significant role in cellulose digestibility of glycerol treated biomass. Syringyl to guaicyl ratio had a significant $(\mathrm{p}<0.05)$ negative impact on cellulose digestibility (Supplementary data Table 1). Higher guaicyl content facilitates xylan removal (Li et al., 2016a), which improves the accessibility of cellulose to cellulase for efficient digestibility. Though the level of lignin removal varied significantly between the post rainy varieties, there was no variation in cellulose's digestibility. These results indicate that lignin removal is not a significant factor in improving the digestibility of cellulose. A significant negative correlation $(p<0.05)$ was obtained for the amount of extractives with the xylan recovery after glycerol pretreatment (Supplementary data Fig. 2). The sorghum varieties with a high amount of extractives, which mainly constitute sugars, showed a high level of xylan removal. This trend is due to the breakage of glycosidic linkages between these sugars and xylan (Rowell et al., 2005). A significant positive correlation $(p<0.05)$ was observed between xylan content in the biomass and xylan recovery (Supplementary data Table 2). The varieties with higher xylan content showed lower xylan removal while the concentrations of cellulose and lignin had a significant impact on the removal of xylan during glycerol pretreatment. The removal of xylan decreased when the contents of lignin and cellulose were high in the biomass. It was due to the interactions of cellulose and lignin with xylan through hydrogen bonds and ether linkages, which act as a barrier for the breakdown of xylan (Yue et al., 2018; Zhang et al., 2015). Whereas, the removal of lignin was not dependent on the cell wall components. The glycerol pretreatment increased the cellulose digestibility of sorghum biomass due to the removal of both xylan and lignin. It is reported

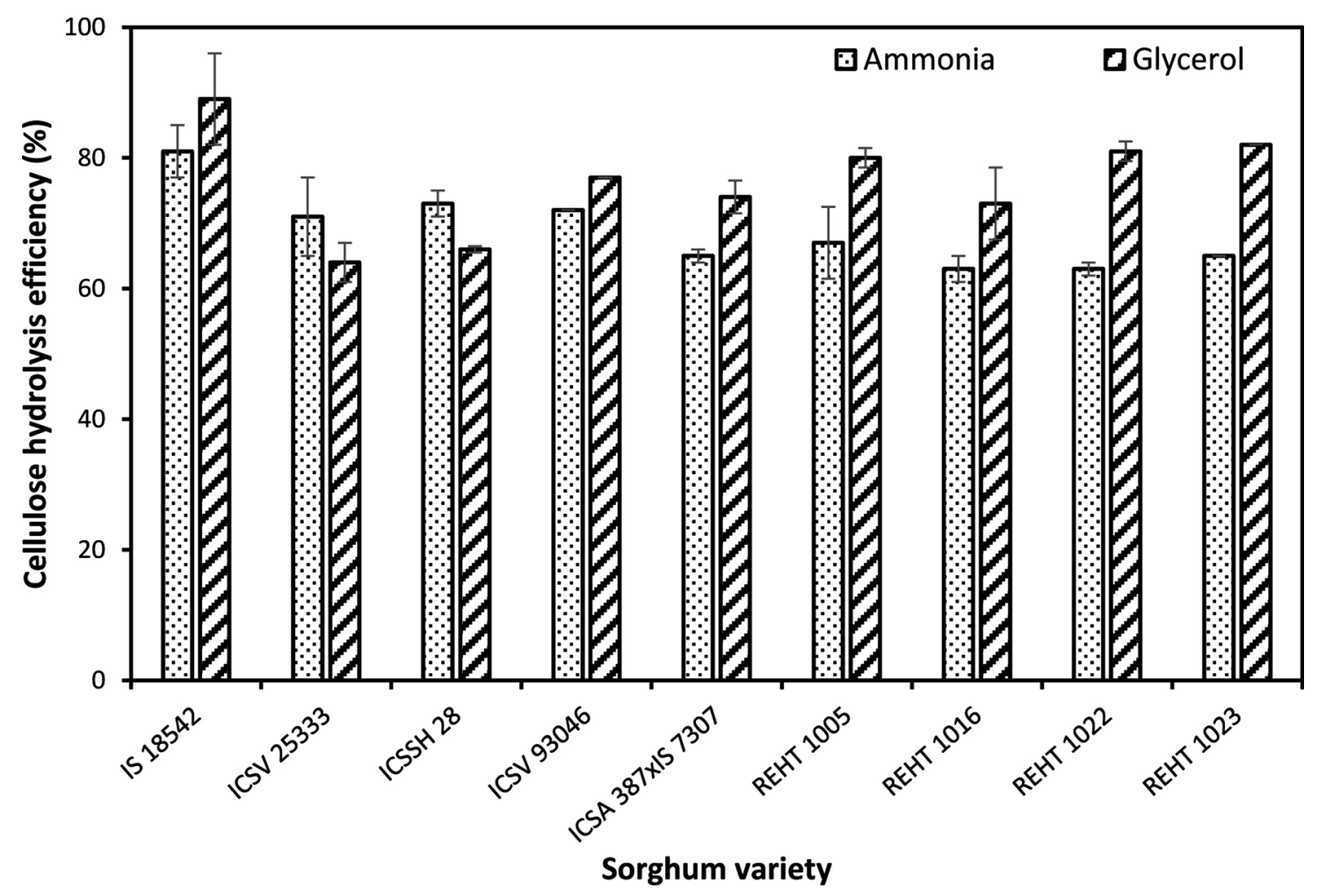

Fig. 6. Comparison of cellulose hydrolysis efficiency of glycerol and ammonia pretreated sorghum varieties. 


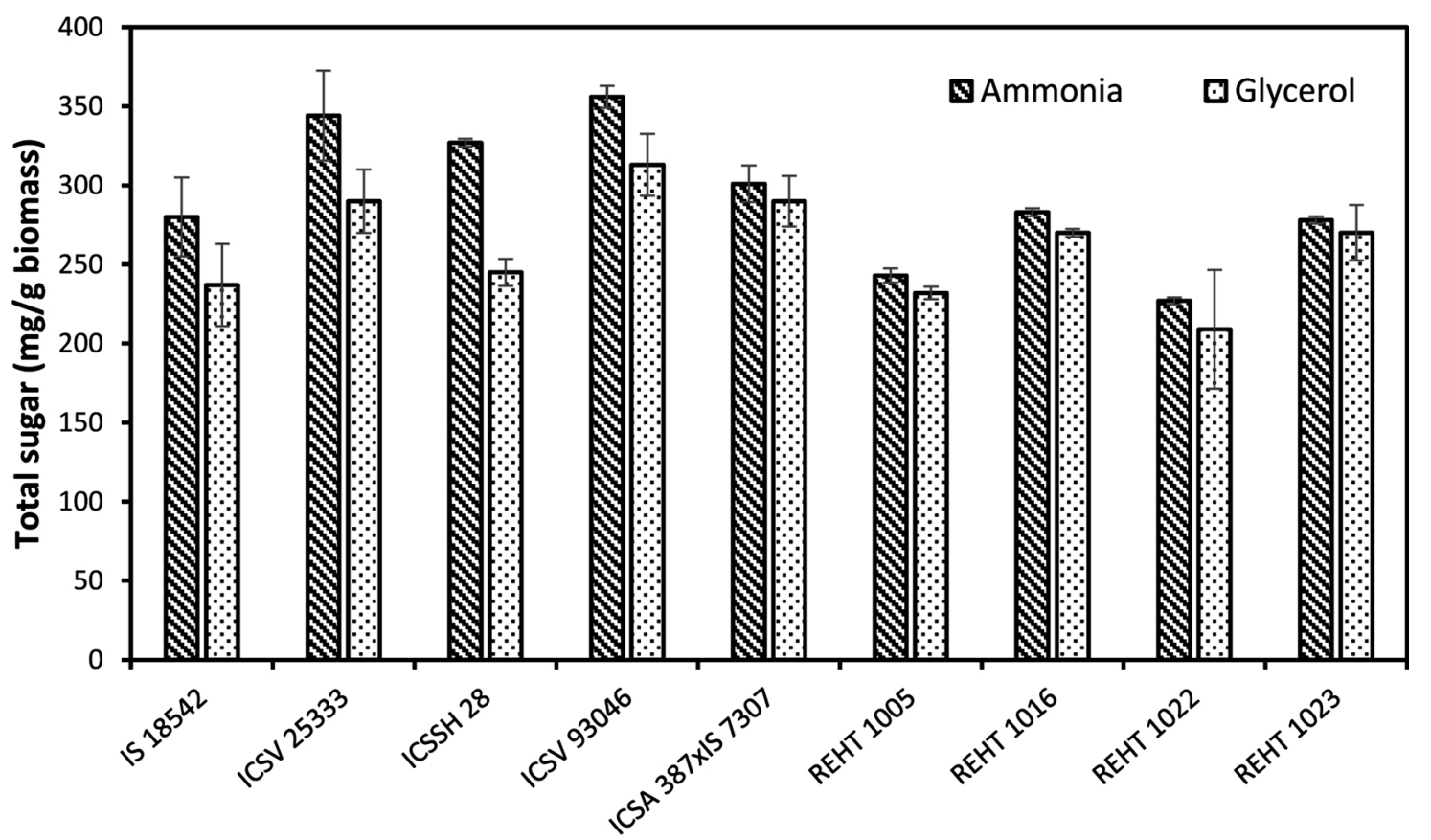

\section{Sorghum variety}

Fig. 7. Comparison of total sugar released after glycerol and ammonia pretreatment of sorghum varieties.

that the removal of xylan and lignin in wheat straw and rice straw after glycerol pretreatment improved the sugar yield (Sun et al., 2015; Trinh et al., 2016).

\subsection{Effect of ammonia pretreatment on sorghum genotypes}

Ammonia pretreated biomass showed minimum carbohydrate loss along with delignification. As seen in Table 4, ammonia pretreatment resulted in lignin removal in all sorghum varieties while preserving 100 $\%$ cellulose and $>80 \%$ xylan in the biomass. Similar results have been reported for ammonia pretreatment of different biomass (Domanski et al., 2016). The cleavage of the phenolic bond between lignin and carbohydrates results in removing lignin (Mussatto, 2016; Yang et al., 2014). A significant difference $(\mathrm{p}<0.05)$ in the cellulose digestibility between sweet sorghum and post rainy sorghum variety was observed after ammonia pretreatment (Fig. 5). The sweet sorghum genotype showed higher saccharification yield than post rainy varieties with IS18542 giving a maximum glucose yield of $81 \%$. There was no significant variation in xylan hydrolysis between the two varieties. Higher hydrolysis yield for sweet sorghum compared to post rainy could be due to the structural changes that happened during ammonia pretreatment, which favored sweet sorghum biomass over post rainy sorghum. The hybrid variety ICSA 387xIS 7307 showed a similar profile as that of post

Table 5

Crystallinity index of raw, glycerol and ammonia pretreated sorghum varieties.

\begin{tabular}{|c|c|c|c|}
\hline \multirow{2}{*}{ Sorghum variety } & \multicolumn{3}{|l|}{ CrI \% } \\
\hline & Untreated & Glycerol pretreated & Ammonia pretreated \\
\hline IS 18542 & 24 & 48 & 47 \\
\hline ICSV 25333 & 37 & 43 & 52 \\
\hline ICSA387xIS 7307 & 37 & 47 & 54 \\
\hline ICSSH 28 & 33 & 42 & 53 \\
\hline ICSV 93046 & 36 & 43 & 53 \\
\hline REHT 1005 & 32 & 48 & 53 \\
\hline REHT 1016 & 35 & 44 & 46 \\
\hline REHT 1022 & 28 & 52 & 49 \\
\hline REHT 1023 & 34 & 49 & 53 \\
\hline
\end{tabular}

rainy variety. Ammonia pretreatment was found to be favorable for sweet sorghum genotypes. However, no correlation could be observed between delignification and cellulose digestibility in sweet sorghum and post rainy sorghum genotypes.

\subsection{Comparison of glycerol and ammonia pretreated on cellulose digestibility and sugar yield from different sorghum genotypes}

Both glycerol and ammonia pretreatments improved the cellulose digestibility of all sorghum varieties by improving the cellulose's accessibility to cellulases. As shown in Fig. 6, the cellulose saccharification was significantly $(\mathrm{p}<0.05)$ higher for glycerol pretreated biomass than ammonia pretreated biomass for all the varieties of sorghum biomass. The sweet sorghum and post rainy varieties showed significant variations with both ammonia and glycerol pretreatment. Sorghum variety IS 18542 showed maximum cellulose hydrolysis efficiencies of $89 \%$ and $81 \%$ for glycerol and ammonia pretreated biomass, respectively. The observed higher efficiency of hydrolysis was due to the maximum removal of lignin and xylan from sorghum variety IS 18541 by the pretreatments. The higher cellulose digestibility for glycerol pretreated biomass was due to the removal of both xylan and lignin. These results showed that both xylan and lignin acted as barriers for cellulase. Lignin is the primary inhibitor of cellulases due to its nonproductive and irreversible binding of cellulases and the formation of a protective cover over cellulose fibers that restrict cellulose exposure (Li and Zheng, 2017). Xylan's effect is also known to occur by inhibition of cellulase due to xylooligomers formed in enzymatic hydrolysis (Qing et al., 2010). Despite higher delignification after ammonia pretreatment, the cellulose digestibility was lower than glycerol pretreatment, thereby proving that cellulose accessibility depends on both delignification and xylan removal. Higher delignification could also result in the closure of pores, which would also reduce hydrolysis efficiency. It is reported that solvent-based pretreatment enhances the cellulose digestibility compared to ammonia pretreatment, as it mainly increases accessibility, confirming that exposure of enzymes to the substrate is more important than just delignification (Rollin et al., 2011). As per ANOVA analysis, there was a significant variation between sweet and post sorghum 
varieties to ammonia and glycerol pretreatment. Glycerol pretreatment was more favorable for improving the cellulose digestibility for post rainy varieties, whereas ammonia pretreatment could be preferred for sweet sorghum varieties. It can be hypothesized that the variation in extractive content between sweet and post rainy sorghum varieties is the deciding factor for the type of pretreatment. Higher extractives in the post rainy varieties facilitate the removal of xylan during glycerol pretreatment, thereby increasing the saccharification yield, as seen in Supplementary data Fig. 2 \& 3. Similarly, Li et al. (2016b) have reported that a higher amount of extractives reduced the cellulose digestibility of liquid hot water pretreated corn stover. During ammonia pretreatment, it was observed that extractives played no role, and the hydrolysis was driven due to the efficient lignin removal. Xylan hydrolysis, however, did not differ significantly between glycerol and ammonia pretreated biomass for all sorghum varieties.

The total sugar yield from sorghum biomass was calculated to screen the sorghum variety giving maximum sugars for ethanol production. Sorghum variety ICSV 93046 gave the maximum sugar yield irrespective of the pretreatment method (Fig. 7). The total sugar yield difference was significant $(\mathrm{p}<0.05)$ between glycerol and ammonia pretreated biomass. Higher sugar yield from ammonia pretreatment was due to the minimum loss of carbohydrates. Although the cellulose hydrolysis efficiency was maximum for IS 18542 variety, sugar yield was low due to the lower cellulose and xylan content in the biomass. Hence, while selecting feedstock for ethanol production, the carbohydrate content is equally essential together with digestibility for higher sugar yield, which would reduce the cost of the ethanol production process (Mezule et al., 2015).

\subsection{Structural analysis of glycerol and ammonia pretreated sorghum biomass}

\subsubsection{X-ray diffraction (XRD) analysis}

$\mathrm{X}$-ray diffraction analysis of untreated and pretreated biomass shows important co-relations of crystallinity of biomass with cellulose digestibility for all sorghum varieties. The XRD pattern of untreated and pretreated biomass of all nine sorghum varieties is shown in the supplementary data Fig. 4. The crystallinity of biomass increased after glycerol and ammonia pretreatment due to the removal of the amorphous portion. The XRD pattern for sweet sorghum genotype and post rainy variety showed differences. Ammonia pretreatment has also shown the formation of cellulose $\mathrm{III}_{\mathrm{I}}$ isoform in all nine sorghum varieties, as evident from the peak at $2 \Theta=35^{\circ}$ (Supplementary data Fig.4). Ammonia pretreatment of corn stover at higher temperatures has been reported to increase the crystallinity and generate cellulose $\mathrm{III}_{\mathrm{I}}$ isoform (Mittal et al., 2017). The crystallinity index (CrI) is a measure of the crystallinity of cellulose in the biomass. The values of the crystallinity index of untreated, glycerol pretreated, and ammonia pretreated sorghum varieties are shown in Table 5. The CrI for untreated biomass varied from $24 \%$ to $37 \%$. IS18542 sorghum variety showed the minimum CrI of $24 \%$ as its cellulose content was very low at $20 \%$. The cellulose content in the biomass significantly $(\mathrm{p}<0.01)$ dictates the crystallinity of the cellulose. As shown earlier, this variety had the maximum cellulose hydrolysis efficiency and delignification. Hence, there exists a correlation of cellulose digestibility with the CrI of biomass. It was observed that $\mathrm{CrI}$ of untreated biomass had a significant ( $p<0.05$ ) negative correlation with the cellulose hydrolysis efficiency of glycerol pretreated biomass. Accordingly, lower crystallinity of biomass favored higher saccharification (Supplementary data Fig. 5A). The higher crystalline structure of cellulose makes it difficult for the penetration of cellulases due to the tight structure and hence lowers the hydrolysis rate (Hall et al., 2010). Thus, while screening for biomass with a lower crystallinity index, which will help in better digestibility, the cellulose content should also be considered as it is interrelated. Both parameters need to be analyzed before choosing the right variety for maximum sugar yield. Interestingly, no such correlation could be seen between CrI of untreated biomass with cellulose hydrolysis of ammonia pretreated sorghum varieties. The presence of xylan recovered in ammonia pretreated biomass acts as a barrier for enzymes, and hence showing that CrI has a reduced effect on saccharification yield in the presence of xylan. The CrI increases significantly $(\mathrm{p}<0.05)$ after glycerol and ammonia pretreatment, as shown in Table 5, due to the removal of the amorphous portion during pretreatment (He et al., 2016). However, the glycerol pretreated biomass had significantly $(\mathrm{p}<0.01$ ) lower crystallinity than ammonia pretreated biomass although, both hemicellulose and lignin were removed. Under a higher temperature of $190^{\circ} \mathrm{C}$ for a longer time, glycerol interacts significantly with cellulose structure and reduces its crystallinity (Trinh et al., 2016). The sweet sorghum varieties showed higher crystallinity after ammonia pretreatment than glycerol pretreatment, whereas, for post rainy sorghum biomass, glycerol pretreatment showed higher crystallinity compared to ammonia (Supplementary data Fig.4). Sweet sorghum varieties have higher cellulose content than post rainy varieties due to which the interaction of glycerol with cellulose is prominent, and hence they show lower crystalline nature compared with ammonia pretreatment. Since glycerol pretreatment of post rainy sorghum varieties showed effective removal of both xylan and lignin compared to sweet sorghum, the crystallinity was higher for glycerol pretreated biomass than ammonia pretreatment. A significant $(\mathrm{p}<0.05)$ positive correlation can be seen between CrI of glycerol pretreated biomass and cellulose digestibility, whereas a significant negative correlation was obtained between CrI of untreated biomass with cellulose digestibility as seen in Supplementary data Fig.5 (A)\&(B). The xylan removal significantly $(\mathrm{p}<0.01)$ increased the crystallinity (Supplementary data Fig.6). No such correlation could be obtained from the CrI of ammonia pretreated biomass with cellulose digestibility as there was no xylan loss.

\subsubsection{Fourier transform infra-red (FTIR) analysis}

The FTIR spectra of all nine untreated sorghum varieties are shown in Supplementary data Fig. 7. It would help us understand the differences in the cell wall component structures of different sorghum biomass, thereby shedding light on the factors that contribute to higher cellulose digestibility in some varieties. Bands at $3295 \mathrm{~cm}^{-1}(\mathrm{O}-\mathrm{H}$ stretching), $2919 \mathrm{~cm}^{-1}\left(\mathrm{C}-\mathrm{H}, \mathrm{CH}_{2}\right.$ stretching $)$ are the characteristic peaks of cellulose. Vibration in ester bond $\mathrm{C}=\mathrm{O}$ in the hemicellulose is observed at $1724 \mathrm{~cm}^{-1}$ (Ebrahimi et al., 2017; Kahar, 2013). Distinct peaks were observed for these regions. These stretchings were found less intense for sorghum varieties ICSV 25333 and ICSV 93046. The peak at $1724 \mathrm{~cm}^{-1}$ is not differentiated well as the hemicellulose content is not significantly different in all sorghum varieties. The glycoside peak $\left(\mathrm{C}-\mathrm{O}-\mathrm{C}\right.$ ) at wave number $1025 \mathrm{~cm}^{-1}$ intensified due to increased cellulose content after glycerol and ammonia pretreatment. The $\mathrm{C}-\mathrm{O}$ bonding in crystalline cellulose is shown at wave number $1025 \mathrm{~cm}^{-1}$, peaks are well defined in all sorghum varieties. The peak at $890 \mathrm{~cm}^{-1}$ is contributed by the $\beta$ - glycosidic bond of amorphous cellulose (He et al., 2016), which is seen reduced after glycerol pretreatment due to the removal of the amorphous portion. The difference in untreated, glycerol, and ammonia pretreated biomass is depicted in Supplementary data Fig.8. The characteristic hemicellulose peak at $1732 \mathrm{~cm}^{-1}$ disappeared after glycerol pretreatment for all sorghum varieties. The decrease in the peak intensity at $1697 \mathrm{~cm}^{-1}, 1507 \mathrm{~cm}^{-1}$, and $1237 \mathrm{~cm}^{-1}$, the attributes of lignin and lignin degraded phenolics (Corredor et al., 2009; Kahar, 2013) were observed for glycerol pretreated and ammonia pretreated IS 18542 biomass. The aromatic ring stretching of lignin; (Guiacyl ring stretching) is observed at wave number $1512 \mathrm{~cm}^{-1}$, which is not distinctly different for all sorghum varieties except ICSV 25333 due to its higher lignin content. The region $1242-1247 \mathrm{~cm}^{-1}$ shows $\mathrm{C}-\mathrm{O}-\mathrm{H}$ and C-O stretching of phenolics (Corredor et al., 2009). The FTIR analysis showed that the Syringyl to Guiacyl ratio (S/G) affect glycerol pretreatment and enzymatic hydrolysis of sorghum biomass. A similar observation was done by Corredor et al. (2009), stating that guaicyl rings' presence resulted in easier removal of hemicellulose and lignin. 
$\mathrm{S} / \mathrm{G}$ ratio plays a vital role in cellulose and xylan hydrolysis, as seen in Supplementary data Table 2. It can be seen that a higher $S / G$ ratio lowered cellulose and xylan hydrolysis. Such a negative correlation has also been reported by (Li et al., 2016a), which contrasts with other reports showing that guaicyl units offer physical hindrance to the enzyme, thereby lowering the hydrolysis efficiency. Such correlations were not obtained for ammonia pretreated sorghum, where $\mathrm{S} / \mathrm{G}$ ratio did not affect the cellulose and xylan hydrolysis.

\subsubsection{Thermogravimetric (TG) analysis}

The sorghum varieties were analyzed for the thermal degradation of cell wall components at its decomposition temperature using thermogravimetric analysis. The changes in the decomposition of its structural components after glycerol and ammonia pretreatment were observed in all sorghum varieties (Supplementary data Fig.9). The vaporization of water molecules was observed at $80 \mathrm{C}$ for all the untreated and pretreated samples. The observed decomposition temperatures at 300 $350 \circ \mathrm{C}, 200-300 \mathrm{C}$, and $>370 \circ \mathrm{C}$ correspond to cellulose, hemicellulose, and lignin, respectively (Ebrahimi et al., 2017). As shown in the TGA curves, glycerol pretreated biomass has an extra decomposition weight loss observed at $150 \circ \mathrm{C}$ due to the volatilization of phenolics released during lignin breakdown. It is consistent with reported results for glycerol microwave pretreated rice husk (Diaz et al., 2015). The degradation of the glycerol pretreated biomass was initiated sooner than untreated, and ammonia pretreated samples, which could be due to the removal of both hemicellulose and lignin, which makes the biomass amenable for degradation. The increase in crystalline cellulose content after pretreatment was observed in the TGA profile, as there was a shift in the decomposition temperature corresponding to cellulose after pretreatment. It is because of the higher stability of crystalline cellulose in the pretreated biomass (Zhang and Wu, 2014). After thermal decomposition, the residual weight of biomass varied from $9 \%$ to $21 \%$ and $17 \%-$ $21 \%$ for glycerol pretreated biomass and ammonia pretreated biomass, respectively.

\subsubsection{Scanning electron microscopy (SEM)}

The morphological changes in sorghum biomass structure after glycerol and ammonia pretreatment were observed with scanning electron microscopy, as shown in Supplementary data Fig.10. There were no significant variations in the morphology of untreated sorghum varieties. It shows biomass in the form of an intact rigid, smooth bundle of fibrils with some deposits on the surface. For post rainy sorghum varieties REHT 1005, REHT 1016, REHT 1022, and REHT 1023, there were some droplets on the surface, which could be the starch granules. Similar morphology due to the deposition of starch granules on the sweet sorghum bagasse surface has been reported (Choudhary et al., 2012). The sorghum varieties showed open pores after glycerol pretreatment and complete distortion due to severe cell wall disruption and erosion. The glycerol pretreated biomass was more porous as compared to ammonia pretreated biomass. It is due to the removal of hemicellulose along with lignin after glycerol pretreatment. Hemicellulose and lignin removal improve the porosity of biomass (Chen et al., 2007; Zoghlami and Paës, 2019). Due to the porous structure, cellulase enzymes can penetrate easily and hydrolyze cellulose, increasing cellulose digestibility (Junior et al., 2013). Such porous nature of biomass was not observed after ammonia pretreatment. These morphological changes confirm the reason for the higher saccharification yield for glycerol pretreated biomass.

\section{Conclusion}

The variations in sorghum biomass varieties' saccharification after glycerol and ammonia pretreatments reflected their structural components' role. The effect of pretreatment on hydrolysis varies with the type of sorghum. The glycerol pretreatment favored post rainy varieties compared to sweet sorghum due to the variation in the extractive content in the sorghum variety, which plays a vital role during glycerol pretreatment in removing hemicellulose. The cell wall components governed the hemicellulose removal. Thus, variations in pretreatment type lie in the structural and compositional differences among the sorghum varieties. The cellulose digestibility was higher for the glycerol pretreated sorghum biomass than the ammonia pretreated sorghum biomass. Because glycerol pretreatment removed hemicellulose and lignin, the cellulose accessibility and the saccharification yield increased. Although lignin is the major barrier for enzymatic hydrolysis, substrate accessibility to enzymes is a major critical factor for higher yield. Sorghum variety, IS 18542, showed maximum cellulose hydrolysis efficiency irrespective of pretreatment type due to its lower crystallinity and maximum delignification. The total sugar yield was maximum from ICSV 93046 sorghum variety for both types of pretreatments. The results showed that both cell wall composition and cellulose crystallinity affected the saccharification yield. Therefore, screening of biomass for higher digestibility of cellulose, cell wall composition is essential. The $\mathrm{S} / \mathrm{G}$ ratio also played a crucial role during glycerol pretreatment, but it showed no effect during ammonia pretreatment. However, the total sugar yield was more for ammonia pretreated sorghum than glycerol pretreated due to the minimum loss of hemicellulose and cellulose. The pretreatment strategy needs to be devised to improve the enzyme accessibility without losing much of the structural carbohydrates. Based on the study, we can conclude that the type of sorghum is the deciding factor for choosing the pretreatment methodology. Hence, the biomass's structural and cell wall compositional factors need to be analyzed for selecting the appropriate pretreatment technique for the efficient release of sugars.

\section{CRediT authorship contribution statement}

Shereena P. Joy: Conceptualization, Methodology, Writing - original draft. A. Ashok Kumar: Supervision. Sunita Gorthy: Resources, Formal analysis. Jayakumar Jaganathan: Resources, Formal analysis. Anil Kunappareddy: Resources, Formal analysis. Anil Gaddameedi: Resources, Formal analysis. Chandraraj Krishnan: Supervision.

\section{Declaration of Competing Interest}

The authors declare that they have no known competing financial interests or personal relationships that could have appeared to influence the work reported in this paper.

\section{Acknowledgements}

The authors greatly acknowledge IIT Madras for the award of half time teaching assistantship to Shereena Joy.

\section{Appendix A. Supplementary data}

Supplementary material related to this article can be found, in the online version, at doi:https://doi.org/10.1016/j.indcrop.2020.113072.

\section{References}

Bensah, E.C., Mensah, M.Y., 2018. Emerging physico-chemical methods for biomass pretreatment. Fuel Ethanol Production From Sugarcane. IntechOpen.

Bhutto, A.W., Qureshi, K., Harijan, K., Abro, R., Abbas, T., Bazmi, A.A., Karim, S., Yu, G., 2017. Insight into progress in pretreatment of lignocellulosic biomass. Energy 122, 724-745.

Cha, Y.-L., Yang, J., Ahn, J.-W., Moon, Y.-H., Yoon, Y.-M., Yu, G.-D., An, G.H., Choi, I.-H., 2014. The optimized CO 2-added ammonia explosion pretreatment for bioethanol production from rice straw. Bioprocess Biosyst. Eng. 37 (9), 1907-1915.

Chen, Y., Sharma-Shivappa, R.R., Keshwani, D., Chen, C., 2007. Potential of agricultural residues and hay for bioethanol production. Appl. Biochem. Biotechnol. 142 (3), 276-290.

Choudhary, R., Umagiliyage, A.L., Liang, Y., Siddaramu, T., Haddock, J., Markevicius, G., 2012. Microwave pretreatment for enzymatic saccharification of sweet sorghum bagasse. Biomass Bioenergy 39, 218-226. 
Corredor, D., Salazar, J.M., Hohn, K., Bean, S., Bean, B., Wang, D., 2009. Evaluation and characterization of forage sorghum as feedstock for fermentable sugar production. Appl. Biochem. Biotechnol. 158 (1), 164.

Demirbas, A., 2010. Direct and alkaline glycerol liquefaction of hazelnut shell. Energy Sources Part A Recovery Util. Environ. Eff. 32 (8), 689-696.

Diaz, A.B., de Souza Moretti, M.M., Bezerra-Bussoli, C., Nunes, Cd.C.C., Blandino, A., da Silva, R., Gomes, E., 2015. Evaluation of microwave-assisted pretreatment of lignocellulosic biomass immersed in alkaline glycerol for fermentable sugars production. Bioresour. Technol. 185, 316-323.

Domanski, J., Borowski, S., Marchut-Mikolajczyk, O., Kubacki, P., 2016. Pretreatment of rye straw with aqueous ammonia for conversion to fermentable sugars as a potential substrates in biotechnological processes. Biomass Bioenergy 91, 91-97.

Ebrahimi, M., Villaflores, O.B., Ordono, E.E., Caparanga, A.R., 2017. Effects of acidified aqueous glycerol and glycerol carbonate pretreatment of rice husk on the enzymatic digestibility, structural characteristics, and bioethanol production. Bioresour. Technol. 228, 264-271.

Gupta, R., Lee, Y., 2010. Investigation of biomass degradation mechanism in pretreatment of switchgrass by aqueous ammonia and sodium hydroxide. Bioresour. Technol. 101 (21), 8185-8191.

Guragain, Y.N., De Coninck, J., Husson, F., Durand, A., Rakshit, S.K., 2011. Comparison of some new pretreatment methods for second generation bioethanol production from wheat straw and water hyacinth. Bioresour. Technol. 102 (6), 4416-4424.

Hall, M., Bansal, P., Lee, J.H., Realff, M.J., Bommarius, A.S., 2010. Cellulose crystallinity-a key predictor of the enzymatic hydrolysis rate. FEBS J. 277 (6), 1571-1582.

He, Y.-C., Liu, F., Di, J.-H., Ding, Y., Gao, D.-Z., Zhang, D.-P., Tao, Z.-C., Chong, G.-G., Huang, M.-Z., Ma, C.-L., 2016. Effective pretreatment of dilute NaOH-soaked chestnut shell with glycerol-HClO 4-water media: structural characterization, enzymatic saccharification, and ethanol fermentation. Bioprocess Biosyst. Eng. 39 (4), 533-543.

Hundt, M., Engel, N., Schnitzlein, K., Schnitzlein, M.G., 2016. The AlkaPolP process: Fractionation of various lignocelluloses and continuous pulping within an integrated biorefinery concept. Chem. Eng. Res. Des. 107, 13-23.

Ibeto, C., Ofoefule, A., Agbo, K., 2011. A global overview of biomass potentials for bioethanol production: a renewable alternative fuel. Trends Appl. Sci. Res. 6 (5), 410-425.

Jönsson, L.J., Martín, C., 2016. Pretreatment of lignocellulose: formation of inhibitory by-products and strategies for minimizing their effects. Bioresour. Technol. 199, 103-112.

Junior, C.S., Milagres, A.M.F., Ferraz, A., Carvalho, W., 2013. The effects of lignin removal and drying on the porosity and enzymatic hydrolysis of sugarcane bagasse. Cellulose 20 (6), 3165-3177.

Kahar, P., 2013. Synergistic effects of pretreatment process on enzymatic digestion of rice straw for efficient ethanol fermentation. Environmental Biotechnology-New Approaches and Prospective Applications. InTech, Croatia, pp. 65-87.

Kang, Q., Appels, L., Tan, T., Dewil, R., 2014. Bioethanol from lignocellulosic biomass: current findings determine research priorities. Sci. World J. 2014.

Kim, J.S., Lee, Y., Kim, T.H., 2016. A review on alkaline pretreatment technology for bioconversion of lignocellulosic biomass. Bioresour. Technol. 199, 42-48.

Kumar, R., Tabatabaei, M., Karimi, K., Sárvári Horváth, I., 2016. Recent updates on lignocellulosic biomass derived ethanol-A review. Biofuel Res. J. 3 (1), 347-356.

Li, M., Feng, S., Wu, L., Li, Y., Fan, C., Zhang, R., Zou, W., Tu, Y., Jing, H.-C., Li, S., 2014 Sugar-rich sweet sorghum is distinctively affected by wall polymer features for biomass digestibility and ethanol fermentation in bagasse. Bioresour. Technol. 167, 14-23.

Li, M., Pu, Y., Ragauskas, A.J., 2016a. Current understanding of the correlation of lignin structure with biomass recalcitrance. Front. Chem. 4, 45.

Li, Z., Yu, Y., Sun, J., Li, D., Huang, Y., Feng, Y., 2016b. Effect of extractives on digestibility of cellulose in corn stover with liquid hot water pretreatment BioResources 11 (1), 54-70.

Li, X., Zheng, Y., 2017. Lignin-enzyme interaction: mechanism, mitigation approach, modeling, and research prospects. Biotechnol. Adv. 35 (4), 466-489.

Martin, C., Puls, J., Saake, B., Schreiber, A., 2011. Effect of glycerol pretreatment on component recovery and enzymatic hydrolysis of sugarcane bagasse. Cellulose Chem. Technol. 45 (7), 487.

Mezule, L., Dalecka, B., Juhna, T., 2015. Fermentable sugar production from lignocellulosic waste. Chem. Eng. Trans. 43, 619-624.

Mittal, A., Katahira, R., Donohoe, B.S., Pattathil, S., Kandemkavil, S., Reed, M.L., Biddy, M.J., Beckham, G.T., 2017. Ammonia pretreatment of corn stover enables facile lignin extraction. ACS Sustain. Chem. Eng. 5 (3), 2544-2561.

Mou, H., Wu, S., 2017. Comparison of hydrothermal, hydrotropic and organosolv pretreatment for improving the enzymatic digestibility of bamboo. Cellulose 24 (1), 85-94.

Mussatto, S.I., 2016. Biomass Fractionation Technologies for a Lignocellulosic Feedstock Based Biorefinery. Elsevier.
Nagaiah, D., Srinivasa Rao, P., Prakasham, R., 2012. High biomass sorghum as a potential raw material for biohydrogen production: a preliminary evaluation. Curr. Trends Biotechnol. Pharm. 6 (2), 183-189.

Nasidi, M., Agu, R., Walker, G.M., Deeni, Y.Y., 2019. Sweet sorghum: agronomic practice for food, animal feed and fuel production in sub-Saharan Africa. Sweet Sorghum: Characteristics, Cultivation and Uses. Nova Science Publishers, Inc.

Park, S., Baker, J.O., Himmel, M.E., Parilla, P.A., Johnson, D.K., 2010. Cellulose crystallinity index: measurement techniques and their impact on interpreting cellulase performance. Biotechnol. Biofuels 3 (1), 10.

Phitsuwan, P., Sakka, K., Ratanakhanokchai, K., 2013. Improvement of lignocellulosic biomass in planta: a review of feedstocks, biomass recalcitrance, and strategic manipulation of ideal plants designed for ethanol production and processability. Biomass Bioenergy 58, 390-405.

Qi, X., Chu, J., Jia, L., Kumar, A., 2019. Influence of different pretreatments on the structure and hydrolysis behavior of Bamboo: a comparative study. Materials 12 (16), 2570.

Qing, Q., Yang, B., Wyman, C.E., 2010. Xylooligomers are strong inhibitors of cellulose hydrolysis by enzymes. Bioresour. Technol. 101 (24), 9624-9630.

Reddy, B., Ramesh, S., Reddy, P., 2004. Sorghum breeding research at ICRISAT-goals, strategies, methods and accomplishments. Int. Sorghum Millets Newsletter 45, 5-12.

Rollin, J.A., Zhu, Z., Sathitsuksanoh, N., Zhang, Y.H.P., 2011. Increasing cellulose accessibility is more important than removing lignin: a comparison of cellulose solvent-based lignocellulose fractionation and soaking in aqueous ammonia. Biotechnol. Bioeng. 108 (1), 22-30.

Rowell, R.M., Pettersen, R., Han, J.S., Rowell, J.S., Tshabalala, M.A., 2005. Cell wall chemistry. Handbook of Wood Chemistry and Wood Composites, p. 2.

Segal, L., Creely, J., Martin Jr., A., Conrad, C., 1959. An empirical method for estimating the degree of crystallinity of native cellulose using the X-ray diffractometer. Text. Res. J. 29 (10), 786-794.

Shoemaker, C.E., Bransby, D.I., 2010. The role of sorghum as a bioenergy feedstock. Sustainable Alternative Fuel Feedstock Opportunities, Challenges and Roadmaps for Six US Regions. Proceedings of the Sustainable Feedstocks for Advanced Biofuel Workshop 149-159.

Sluiter, A., Hames, B., Ruiz, R., Scarlata, C., Sluiter, J., Templeton, D., Crocker, D., 2008. Determination of structural carbohydrates and lignin in biomass. Laboratory Analytical Procedure 1617, 1-16.

Steel, R.G., Torrie, J.H., 1980. Principles and Procedures of Statistics, a Biometrical Approach. McGraw-Hill Kogakusha, Ltd.

Sun, F., Chen, H., 2008. Organosolv pretreatment by crude glycerol from oleochemicals industry for enzymatic hydrolysis of wheat straw. Bioresour. Technol. 99 (13), 5474-5479.

Sun, F.F., Wang, L., Hong, J., Ren, J., Du, F., Hu, J., Zhang, Z., Zhou, B., 2015. The impact of glycerol organosolv pretreatment on the chemistry and enzymatic hydrolyzability of wheat straw. Bioresour. Technol. 187, 354-361.

Swain, M.R., Krishnan, C., 2015. Improved conversion of rice straw to ethanol and xylitol by combination of moderate temperature ammonia pretreatment and sequential fermentation using Candida tropicalis. Ind. Crops Prod. 77, 1039-1046.

Teramura, H., Sasaki, K., Oshima, T., Matsuda, F., Okamoto, M., Shirai, T., Kawaguchi, H., Ogino, C., Hirano, K., Sazuka, T., 2016. Organosolv pretreatment of sorghum bagasse using a low concentration of hydrophobic solvents such as 1butanol or 1-pentanol. Biotechnol. Biofuels 9 (1), 27.

Trinh, L.T.P., Lee, J.-W., Lee, H.-J., 2016. Acidified glycerol pretreatment for enhanced ethanol production from rice straw. Biomass Bioenergy 94, 39-45.

Turhollow, A.F., Webb, E.G., Downing, M.E., 2010. Review of Sorghum Production Practices: Applications for Bioenergy. ORNL/TM-2010/7. Oak Ridge National Laboratory, Tennessee, US. URL: http://info.ornl.gov/sites/publications/files/Pub 22854.pdf (Accessed 2 June 2011). https://doi.org/10.2172/982121.

Vandenbrink, J.P., Hilten, R.N., Das, K., Paterson, A.H., Feltus, F.A., 2012. Analysis of crystallinity index and hydrolysis rates in the bioenergy crop Sorghum bicolor. Bioenergy Res. 5 (2), 387-397.

Yang, Z., Zhang, M., Xin, D., Wang, J., Zhang, J., 2014. Evaluation of aqueous ammonia pretreatment for enzymatic hydrolysis of different fractions of bamboo shoot and mature bamboo. Bioresour. Technol. 173, 198-206.

Yue, P.-P., Hu, Y.-J., Fu, G.-Q., Sun, C.-X., Li, M.-F., Peng, F., Sun, R.-C., 2018. Structural differences between the lignin-carbohydrate complexes (LCCs) from 2-and 24month-old bamboo (Neosinocalamus affinis). Int. J. Mol. Sci. 19 (1), 1.

Zhang, H., Wu, S., 2014. Dilute ammonia pretreatment of sugarcane bagasse followed by enzymatic hydrolysis to sugars. Cellulose 21 (3), 1341-1349.

Zhang, J., Choi, Y.S., Yoo, C.G., Kim, T.H., Brown, R.C., Shanks, B.H., 2015. Cellulose-hemicellulose and cellulose-lignin interactions during fast pyrolysis. ACS Sustain. Chem. Eng. 3 (2), 293-301.

Zhao, X., Cheng, K., Liu, D., 2009. Organosolv pretreatment of lignocellulosic biomass for enzymatic hydrolysis. Appl. Microbiol. Biotechnol. 82 (5), 815.

Zoghlami, A., Paës, G., 2019. Lignocellulosic biomass: understanding recalcitrance and predicting hydrolysis. Front. Chem. 7, 874. 